\title{
Defense Strategy Transition and Economic Growth under External Predation
}

\author{
By Taoxiong Liu, Angang Hu and Bihua Zhou*
}

\begin{abstract}
This paper develops a growth model of a country under a Hobbesian environment with international conflicts where national defense is the only way to prevent external predation. Different defense strategies result in different growth path. The long run growth path is determined by the equilibrium of a dynamic game with three players, the external predator, the government and the family. The equilibrium growth path may have different phases, submissive equilibrium, tolerant equilibrium and complete-protected equilibrium. Sustainable growth will endogenously induce adjustment of defense strategies. As the economy keeps growing, complete protection will eventually be preferred. The optimal growth path would like to compress the length of the transitional period from incomplete protection to complete protection. Some interesting features of the transitional dynamics are exhibited by a control model with discontinuity.

JEL: 041 F52 H56

Keywords: economic growth; predate; defense expenditure
\end{abstract}

In the matter of the external environment of economic growth, the mainstream tradition of economic growth theory pay more attention to international trade and international capital flow, while conflict behavior among countries is usually out of the consideration 11 In fact, the conflict behavior between countries have never stopped, more than that, it is one of the most important research topics on the research of international relationship. Empirical studies also have demonstrated its significance to country's economic growth $2^{2}$ This paper setups a long term growth model of a country under the environment of international conflicts. The focal point of this model is the interrelationship of international conflict, national defense and economic growth, and the new implications after the international conflict and national defense are integrated in the economic growth model.

Many scholars have studied the international conflict by economics approach, especially game theory. In economics, the main thought explaining international structure is: the emergence of nation-state is the equilibrium outcome of the bal-

\footnotetext{
* Liu, School of Humanities and Social Sciences, Tsinghua University, Beijing 100084, China (e-mial: liutx@tsinghua.edu.cn); Hu: School of Public Policy and Management, Tsinghua University, Beijing 100084, China. Zhou: School of Humanities and Social Science, Tsinghua University.

${ }^{1}$ See the discussion about the open economy in Barro and Sala-i-Martin (1992)

${ }^{2}$ See Nye. J. S. (2002) "Understanding International Conflicts: An Introduction to Theory and History". Shanghai: Shanghai People Press. pp. 1-16.3
} 
ance to allocate resources between defense and offense 3 The resource allocation in equilibria is an important characteristic which shows the balanced relationships among countries, and it has inevitable impact and restriction in turn on countries' development. In Friedman (1977) and Boulding (1963), the equilibrium between predation and defense had been analyzed geographically and technically. Whenever the equilibrium takes place, it relies on the two actions' relative technical advantages, returns to scale, usable resources and other factors. Hirshleifer $(1991,2000)$ had discussed these questions in a generalized framework. And other economists (Grossman and Kim 1995, Skaperdas 1992, Garfinkel 1990) have done in-depth study on the micro foundation of resource distribution between predation and defense in some more special models.

In the plenty of research on the national defense, both the political and economic factors have been emphasized by economists, while most of them are not going on under the framework of growth theory. According to this research of defense, national defense is public product, whose demand function is similar to the common public product, and is different from the private product. There are three categories of models of military expenditure demand: the general empirical model, neoclassical model and decision-making process model 4 The first category is mainly from the empirical study, while the third category is mainly from study of the micro decision making process of military expenditure. It is the second category which provides theoretical reference for the relationship between economic growth and national defense, and tells us that, as the result of economic growth, the national income or government revenue impose budget constraints to the military expenditure. In this kind of model, the national income and outside threat is fixed as external variables. The military expenditure's effect on economic growth is ignored, and it is viewed as the investment to produce "security", which enters the utility function directly and determines the total utility together with consumption.

In this paper, the root of the international conflicts is attributed to the economic interest, and it is supposed that the only purpose to pay the military expenditure is to protect the native property from being plundered. The basic idea is: suppose under a Hobbesian environment in which the countries faces the possibility of being plundered all the time. The only way to prevent the external

\footnotetext{
${ }^{3}$ See Sandler, Todd. \& Hartley, Keith. (2001) The Economics Of Defense. Beijing: Economic Science Press, pp. 37.

${ }^{4}$ The characters of these three kinds of models are: the basic method of a general empirical model try to take account of all kinds of factors of national defense, including economy, politics and strategy and so on, and it usually applies them directly into empirical research. Murdoch and Sandler (1985), Looneyand Mehay (1990), Kollias (1994, 1996) have mainly adopted and developed this kind of models, and then they did extensive researches in the U.S., Australia, Greece and Turkey and so on. The neoclassical model's foundation is the assumption of rational government, which considers the purpose of government is to maximize social welfare. As the total resource is finite, it needs to be distributed optimally to private department and public department. Besides, in general, assume that the welfare consists of national security and consumption. The defense expenditure demand model which bases on decision process does not agree with the basic assumption which considers government as an independent rational agent. It pays more attention to the actual process for one country to make decision on the defense expenditure. (See Hartley \& Sandler 2001, pp. 70-85)
} 
predation is to invest for the national defense, and the proportion of one country's total output being protected or plundered is decided by the Contest Success Function (CSF). The economic growth depends on the factor accumulation. At equilibrium, the protection extent influences the marginal return, and therefore influences the factor accumulation. Then, the country has to face the problem of how to optimally allocate resources among consumption, production and national defense. It decides the long term equilibrium growth path that attains both international conflict equilibrium and the balance among consumption, production and national defense. .

The remainder of the paper is arranged as follows, the first section describes the structure and character of the basic model. A dynamic equilibrium growth path is solved in the second section. Section III presents when and how the country would like to implement complete protection if there exist such a way, but costly. The fourth section elaborates further the theoretical meaning of model's result.

\section{Basic Model}

The model analyzes how a country facing external predation attains the equilibrium between the international conflict and the internal economic growth, and what its economic growth path looks like. Suppose the world political and economical system is under the Hobbesian Rule, full of conflicts among countries and the only purpose of the international conflicts is to gain the economic interest 5 Under this kind of international environment, a country has to face many other countries predations all the time. There is a country A in this situation. For simplicity, suppose country A could not plunder other country but try to prevent the external predation. In other words, the conflict between country A and other countries is a predation-defense problem. It is a reasonable assumption when the country is a developing country or it could not pose a threat to other countries. The only way for country A to prevent predation is to invest to the defense department to protect the national property. There are three players in this model: external predator, the government and representative family of country A. The following is the explanation about their behaviors.

\section{A. International Conflict}

Country A, with numerous families which population is standardized to 1 , is facing conflicts with the predators all the time. Assume that the proportion that country A's property is protected from being plundered is decided by the predation and defense spending by both sides through the Contest Success Function. At time $t$, country A's defense expenditure is $F_{d}(t)$, other countries' plundering spendings are $F_{p}(t)$. Denote defense spending per capita as $f$ and predation

\footnotetext{
${ }^{5}$ Though it is controversial to describe the international order in Hobbesian Rule, there are still many scholars who adopt and accept it, and they consider it as the most important difference between international society and domestic society. (See Nye. J. S. 2002, pp.4)
} 
spending per capita (with respect to Country A) as F. Assume the Contest Success Function (CSF) as ${ }^{6}$

$$
p(f, F)=\frac{\theta f+\bar{f}}{\theta f+\bar{f}+F} .
$$

Whenever not inducing confusion, we drop the time variable t. Here $p$ is the proportion of A's property under protection, $\vartheta$ and $\bar{f}$ are technical parameters of conflict 7 As shown in the figure, $p>0$, when $f$ is 0 , which means country A would not lose all of its property even it gives up defense spending. After all, the predation is condemned morally, and it is limited by kinds of factors, such as the international environment, the prey and the predator's internal conditions and cost of wealth transition. Therefore, even if the prey is quite weak, the predator could not take all of its property away, and is used to measure the strength of natural protection when country $\mathrm{C}$ spends no money on defense.

Obviously, the proportion of country A's property being plundered is:

$$
1-p(f, F)=\frac{F}{\theta f+\bar{f}+F}
$$

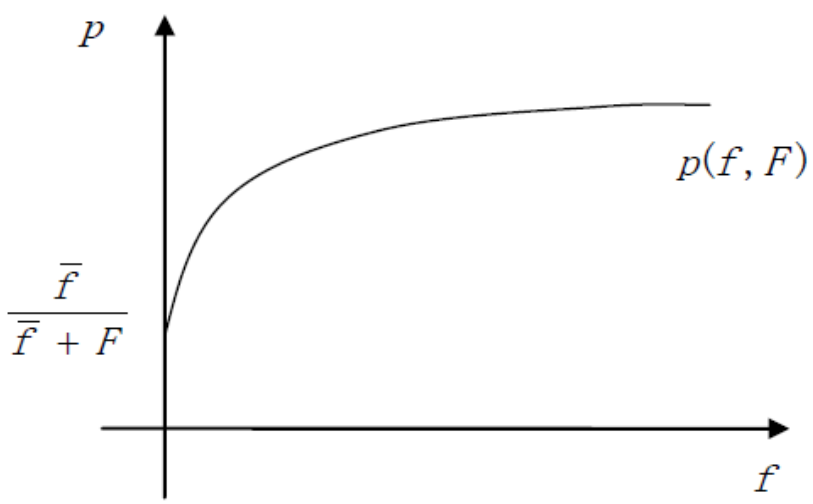

Figure 1. Contest Success Function

\footnotetext{
${ }^{6}$ The conflict economics considers that the conflict process has some essential economic features as same as production process. Just as the most basic means to analyze production process is production function, in the formal economics literature on conflict, they generally adopt some functions to simulate the relationship between input and output of conflict behavior, and these functions are called Contest Success Function (CSF). Hirshleifer $(1989,1994,2000)$ introduce some general function forms. For the application of some functions, see Loury (1979), Tullock (1980), Rosen(1986), Appelbaum and Katz (1987), Dixit (1987), Hirshleifer (1989), Skaperdas (1996), Baik and Lee(2001), Hirshleifer (1989), Baik (1998) and so on.

${ }^{7}$ It is more reasonable that $p$ is decided by the stocks of bilateral conflict inputs. But this has no substantial effect on the theoretical conclusions of this model. For simplicity, we treat conflict inputs as flows.
} 


\section{B. The Behavior of Country A}

Country A is made up of the government and many symmetrical families. As the model is not concerned with the predator's internal government and family, the government and family mentioned in this paper refer only to country A which is plundered. At time $t$, country A spends resources to production as well as defense. It needs to balance between "cannon and butter". The gross income in each period is divided into consumption, investment and defense expenditure, among which, defense expenditure is decided by the government while consumption and investment are decided by the families.

Each family population is standardized to be 1 . As the total amount of families is quite large, we think that the action of a single family has no effect on the aggregate variables. So the symmetry of the families makes the solving process much simpler. Assume that the government who is responsible for maximizing the family lifetime utilities is a rational agent of the public, and finance for defense expenditure by lump-sum taxation 8 Because the families are symmetrical, each family contributes $\mathrm{f}$ to defense expenditure. The national defense is public product, so the protected proportion of each family's output is $p$. Per capita capital stock of country $\mathrm{A}$ is $k$, and the per capita production function is $y(k)$, which is assumed to have the linear form $A k$. Because of the existence of the external predator, the country could not get the overall output, but only $p y(k)$, the remaining output after being plundered. Therefore, at time $t$, the family's budget constraint, i.e. the capital accumulation equation is

$$
\dot{k}=p y-f-c-\delta k,
$$

where $\delta$ is the capital depreciation rate and

$$
f \geq 0
$$

Equation (2) shows that defense expenditure's influence on economic growth is mainly on two aspects: on one hand, the defense expenditure occupies a part of current revenue, so that it may suppress consumption and investment; on the other hand, defense expenditure has effect on the proportion of the product being protected, so that it influences the long term economic growth.

A representative family tries to maximize the objective function:

$$
U=\int_{0}^{\infty} u(c(t)) \cdot e^{-\rho t} d t=\int_{0}^{\infty} \ln (c(t)) \cdot e^{-\rho t} d t
$$

, where the current utility function is assume to be $\ln (c(t))$.

\footnotetext{
${ }^{8}$ The assumption of lump-sum taxation can avoid the influence that the marginal tax rate may decrease the production marginal return.
} 
In a standard growth model, $k(0)$ is a necessary condition. In order to obtain meaningful solutions, assume that the parameters satisfy the following conditions:

$$
\rho \theta>A>(1+\theta)(\rho+\delta) / \theta .
$$

In the following text, at first, we analyze the characteristics of economic growth under different defense strategy assumption. Then, we explain the dynamic equilibrium path where different strategies may occur sequentially.

\section{The Predator's Behavior}

Assume that many predators may prey on country A's property and are ready to plunder all the time. For simplicity, assume that these predators take the chance randomly to plunder country $\mathrm{A}$, and at one time there is one and only one predator. There are too many predators that it is difficult to collude with each other. So once a predator gain the chance, it will try to maximize the profit from this period's predation since in the next period the predation chance may be gained by another predator. Therefore, in this game, the predator's purpose is to maximize each period's profit, not like country A who considers the infinite horizontal problem. The proportion of the property every predator gains from country A is decided by the Contest Success Function. Therefore, the predator's optimization problem is to maximize the current net revenue, which expression is directly written in per capita (with respect to Country A) form.

$$
\begin{aligned}
& \operatorname{Max}[1-p(f, F) y]-F \\
& \text { s.t.F } \geq 0
\end{aligned}
$$

It is easy to solve this problem to find the predator's behavior as

$$
F= \begin{cases}\sqrt{(\theta f+\bar{f}) y}, & y>\theta f+\bar{f} \\ 0 & y \leq \theta f+\bar{f}\end{cases}
$$

Therefore, the model in this paper looks like a partial equilibrium mode. Just as Mejia and Posada (2002) said, if there are many external predators and they haven't colluded with each other, it is reasonable to explain the action by partial equilibrium. 9

\section{The Dynamic Equilibrium}

The dynamic equilibrium involves some complicated technical problems. In the general setting, the model in this paper is not a repeated game model in

\footnotetext{
${ }^{9}$ Thompson (1974) has put forward an idea that every country needs to distribute its wealth into production and security area rationally.
} 
continuous time. It is because, for country A, the production department and conflict department have effect with each other in every period, and different investment or output in every period can also change the conflict problem in every period. Here for simplicity we assume that the player's action only depends on time $t 10$

In this model, the action variables of country A's government is the defense expenditure $f(t)$ and the family's is the consumption $c(t)$ in each period. The predator's action variable is $F(t) 11$ the predation spending per period. The predators pursue the maximization of current profits, while the defenders pursue the maximization of the infinite utilities. The predator's problem is to solve the expression (6). The representative family's problem is to solve problem (4), given predator's action $F(t)$ and government action $f(t)$. The government's problem is to maximize representative family's lifetime utility given predator's choice $F(t)$ and family's choice $c(t)$.

To illustrate the features of the model, we first directly assume specific conflict strategies and explore the growth path under different assumptions. Then we explain how these strategies form a dynamic game equilibrium solution, and analyze the corresponding equilibrium growth path.

\section{A. Growth Path under Different Conflict Strategies}

The following paragraphs are primary analyzes on representative family's optimization problem under the condition that other players' strategies have been given. The current-value Hamilton Equation for the representative family's problem is

$$
\mathcal{H}(\cdot)=\ln c+\mu[p(f, F) A k-f-c-\delta k]
$$

1) Growth Path under Tolerant Strategy

Assume directly that the predator and government's tolerant strategies under the dynamic game are as following (The superscript "\#" shows the value under tolerant strategy).

$$
\left\{\begin{array}{l}
F^{\#}(t)=\frac{\theta}{(1+\theta)^{2}} y(k(t)) \\
f^{\#}(t)=\frac{\theta}{(1+\theta)^{2}} y(k(t))-\frac{\bar{f}}{\theta}
\end{array}\right.
$$

Obviously, in order for the existence of the government's strategy, assume

\footnotetext{
${ }^{10}$ Anther solution concept named Markov Perfect Equilibrium (MPE), for which the player's action is assumed to only depend on some state variable, namely Return Relevant Variable, can also be considered here. In this model, country A's per capita capital stock, $k(t)$, is the appropriate Return Relevant Variable. For this model, the main theoretical results from the approach here and MPE are similar.

${ }^{11}$ Because of the assumption that the predators gain randomly the chance to plunder, the predation input decision in different periods may be decided by different predators.
} 
that the following inequality holds all the time.

$$
y(k) \geq \frac{\theta}{(1+\theta)^{2}} y(k)
$$

From (1),

$$
p(f, F)=\frac{\theta}{1+\theta} \equiv p^{\#} .
$$

In other words, under the assumed condition that both the predator and government adopt the strategy $F^{\#}(k)$ and $f^{\#}(k)$, the protected proportion of country A's output is always $p^{\#}$. It is clear that under the tolerant strategy, country A spend part of its resources on national defense, but part of its output is still plundered. Therefore, its defense expenditure is moderated. This is what the word "tolerant" really means.

THEOREM 1: Assume that the government and predator adopt the tolerant strategy, and $k(0)>(1+\theta)^{2} \bar{f} /\left(A \theta^{2}\right)$, then there is the unique equilibrium growth path. On the path, the capital and consumption always have positive growth rate. Moreover, consumption's growth rate is constant as

$$
\gamma_{c}^{\#}=\frac{A \theta}{1+\theta}-\rho-\delta \equiv \gamma^{\#}
$$

See the proof in the appendix.

2) Growth path under the submissive strategy

The superscript "\&" shows the value under the subject strategy. Assume directly that the predator and government's strategies are as follows:

$$
\left\{\begin{array}{l}
f^{\&}(t)=0 \\
F^{\&}(t)=\sqrt{\bar{f} A k(t)}-\bar{f}
\end{array}\right.
$$

Now country A's defense expenditure is always zero, this is what the word "submissive" means. the validation of expression (11) needs

$$
y(k) \geq \bar{f} .
$$

THEOREM 2: Assume that the government and predator adopt the submissive strategy, and $k(0) \geq \bar{f} / A$, then there is the unique equilibrium growth path, which is tending to the stable status. In the stable status, the values of capital and consumption are determined as

$$
\left\{\begin{array}{l}
k^{\&}=\frac{A \bar{f}}{(\rho+\delta)^{2}} \\
c^{\&}=\frac{\rho A \bar{f}}{(\rho+\delta)^{2}}
\end{array} .\right.
$$


Proof is in the appendix.

3) Growth path under the friendly strategy

The idea here is that there is no conflict under the friendly strategy. Both the predator and the government don't invest anything into conflict. The superscript "\$" shows the value under the friendly strategy. Assume directly that the predator and government's MPE strategies are as follows:

$$
\left\{\begin{array}{l}
f^{\$}(k)=0 \\
F^{\$}(k)=0
\end{array}\right.
$$

According to the expression(1), $p=1$. Now, the model is a standard neoclassical $A k$ growth model, meanwhile the following theorem is presented:

THEOREM 3: Assume that the government and predator adopt the friendly strategy, then the economic system has the unique equilibrium growth path, on which both the consumption and investment have constant growth rate, and following expressions hold

$$
\left\{\gamma_{c}^{\$}=\gamma_{k}^{\$}=A-\rho-\delta \equiv \gamma^{\$}\right.
$$

The proof is omitted.

\section{B. Dynamic Equilibrium Growth Path}

According to the above discussion, with different assumptions for the conflict strategies of the government and predators, there are different equilibrium growth paths for the economy. When the government and predator adopt the tolerant strategy and friendly strategy, consumption has a constant positive growth rate all along, and the growth rate under friendly strategy is higher. While under the submissive strategy, the economy tends to a stable state in which both consumption and capital are fixed.

In the above discussion, the government's strategy is assumed directly. Next we show that all of the above growth paths may appear in the equilibrium path as the the capital stock keeping growing with the assumption of beneficial government, which is presented in the following theorem.

THEOREM 4: Given $k(0)<\bar{f} / A$, predators behavior described as equations (7) and the government acting as a rational agent of the public, the growth path characterizes by following equations is a dynamic equilibrium growth path for the economy. 
1) When $k(t) \leq \bar{f} / A$, the government and predators select friendly strategies as in equations 13 , while the economy grows as described in theorem 3.

2) when $\bar{f} / A<k(t) \leq(1+\theta)^{2} \bar{f} /\left(A \theta^{2}\right)$, the government and predators select submissive strategies as in equations 11 , while the economy grows as described in theorem 2 .

3) when $(1+\theta)^{2} \bar{f} /\left(A \theta^{2}\right)<k(t)$, the government and predators select friendly strategies as in equations $(9)$, while the economy grows as described in theorem 1 .

\section{PROOF:}

Firstly, given the strategies of the families and government, the predator's strategies are optimal since they are the solution of expression (6).

Secondly, from the previous section, we have already known that the family's strategies in each period are optimal, given the action of other player.

Finally, for the government problem, a central planner problem is needed to be considered.

$$
\begin{aligned}
\underset{f(t), c(t)}{\operatorname{Max}} & U=\int_{0}^{\infty} \ln (c(t)) \cdot e^{-\rho t} d t \\
\text { s.t. } & \dot{k}=p y-f-c-\delta k \\
& f \geq 0
\end{aligned}
$$

Write the Hamiltonian

$$
\mathcal{H}(\cdot)=\ln c+\mu[p(f, F) A k-f-c-\delta k]+\lambda f
$$

Here only need the first order condition with respect to $f$,

$$
\frac{\partial \mathcal{H}}{\partial f}=0 \Rightarrow \mu()+\lambda=0
$$

When $\lambda=0, p_{f} A k=1$. It, together with the strategies of predator, means that the government tolerant strategy in expression(9) is optimal when $(1+$ $\theta)^{2} \bar{f} /\left(A \theta^{2}\right) \leq k(t)$.

When $\lambda>0, f=0$. But for the FOC to hold, there must be $p_{f} A k<1$ since $\mu$ and $\lambda$ are nonnegative. Together with the strategies of predator, that meas $(1+\theta)^{2} \bar{f} /\left(A \theta^{2}\right)>k(t)$.

So the government's strategies in each period are optimal given the action of other players

This theorem says that the equilibrium path consists of three periods. In the first period as $k \leq \bar{f} / A$, all players' strategies refer to the situation of friendly strategy. Therefore, there is no conflict and no property being plundered, and the consumption per capita has constant positive growth rate. In the third period as 
$k>(1+\theta)^{2} \bar{f} /\left(A \theta^{2}\right)$, all players' strategies refer to the situation of tolerant strategy. A fixed proportion of the output is plundered, consumption per capita has a constant positive growth rate. In the second period as $\bar{f} / A \leq k \leq(1+\theta)^{2} f /\left(A \theta^{2}\right)$ , all players' strategies refer to the situation of submissive strategy. Consumption per capita and capital stock per capita tend to be a fixed value asymptotically. According to expression (5) and (12), we know the capital stock in the stable state is

$$
k^{\&}=\frac{A \bar{f}}{(\rho+\delta)^{2}}=\frac{A^{2}}{(\rho+\delta)^{2}} \frac{\bar{f}}{A}>\frac{(1+\theta)^{2}}{A \theta^{2}} \bar{f} .
$$

Therefore, the economy must reach the growth path under the tolerant strategy before it reaches the stable state.

Obviously, the above-mentioned phases take place in sequence. The key point is that the growth rates in all phases since beginning is greater than 0 , so that $k$ can keep going up from $k(0)$ until the time when it is greater than $k^{\&}$. In the equilibrium path's first phase, namely the friendly equilibrium phase, the condition to ensure a positive growth rate is the same to the classical growth model. More important is the condition that ensures the economy to evolve from the second phase, namely submissive equilibrium phase into the tolerant equilibrium phase. As part of the expression (5), $\theta A>(1+\theta)(\rho+\delta)$, i.e. $\theta>$ $(\rho+\delta) /(A-\rho-\delta)$. This condition not only ensures the tolerant equilibrium phase's growth rate is positive, but also ensures the above expression holds. Therefore, the economy can reach the growth path under the tolerant strategy before reaching the stable state. As mentioned previously, $\vartheta$ is used to measure the both sides' relative level of technology in conflict, in other words, it is possible to reach the tolerant equilibrium path only if country A's defense technology is above a particular level. Besides, the greater the $\rho$ and $\delta$ are, the higher the lowest-needed value of $\vartheta$. It means that when the future is less important, there must be a higher value of $\vartheta$ to ensure the motivation to pursue the long term positive growth rate.

\section{Optimal Complete Protection}

In the previous part, we give a dynamic equilibrium growth path, on which country A tends to a constant positive growth rate at last. But in this dynamic equilibrium, only when the capital stock is extremely low can the economy be free from being plundered, and as the output increases, there is a fixed proportion of output being plundered all along after the economy reaches the tolerant equilibrium growth path. It is likely that the conclusion is inconsistent with our intuition, because after a country grows strong enough, it should have ability to protect its output completely. The following paragraphs will give a dynamic equilibrium growth path, in which the output is eventually protected completely, while the transition to complete protection exhibit some interesting features.

Suppose that country A can invest in defense department to enhance the capacity of defense. A typical example is to setup strategic weapon system (SWS). The accumulative cost of establishing SWS is $\bar{w}$. let $w(t)$ denote the accumula- 
tive investment or capital stock for SWS and $i_{w}(t)$ denote the investment flow for SWS. Hence

$$
\begin{aligned}
\dot{w} & =i_{w} \\
\bar{w}-w & \geq 0
\end{aligned}
$$

Country A can choose when to initiate the SWS, but she can not interrupt the process once she start the SWS program, i.e. $i_{w} \neq 0$ when $w \in(0, \bar{w})$.

Assume that the predator will never plunder a country with SWS. We can rewrite the protected proportion of country A's output or contest success function as a function of $f, F$ and $w$, instead of equation (1),

$$
p(f, F, w)= \begin{cases}\frac{\theta f+\bar{f}}{\theta f+\bar{f}+F}, & \text { if } w<\bar{w} \\ 1 & \text { if } w=\bar{w}\end{cases}
$$

We assume the predator still solves the problem of (6), where the only change is that now $p$ is determined by (14).

The family's problem still maximizes expression (4) with respect to corresponding constraints. Suppose the government is a rational beneficial of families and try to maximize family lifetime utility by choosing $f(t)$ and $i_{w}(t)$. For simplicity, we assume $\delta=0, \bar{f}=0$. So we can solve a central planner problem to find the behaviors of both families and government as

$$
\begin{aligned}
& \operatorname{Max} \int_{0}^{\infty} \ln c(t) e^{-\rho t} d t \\
& \text { st. } \dot{k}=p(f, F, w) A k-f-i_{w}-c \\
& \quad \dot{w}=i_{w} \\
& \quad f \geq 0 \\
& \quad \bar{w}-w \geq 0 \\
& \quad i_{w} \geq 0 \\
& \quad p(f, F, w) A k-f-i_{w}-c \geq 0
\end{aligned}
$$

The last constraint means that capital stock is irreversible so that productive investment can not be negative.Suppose that SWS starts at time $\tau_{1}$ and is finished at time $\tau_{2}$. We have constraints for this two point as

$$
\begin{aligned}
w\left(t_{1}\right) & =0 \\
w\left(t_{2}\right)-\bar{w} & =0
\end{aligned}
$$

Write the Hamiltonian for the central planner's problem. 


$$
\begin{gathered}
\mathcal{H}(\cdot)=\left(17 h c+\mu_{1}\left[p(f, F, w) A k-f-c-\delta k-i_{w}\right]+\mu_{2} i_{w}+\lambda_{1}(f)+\lambda_{2}(\bar{w}-w)+\lambda_{3}\left(i_{w}\right)\right. \\
\left.+\lambda_{4}(p(f, F, w)) A k-f-i_{w}-c-\delta k\right)
\end{gathered}
$$

and let

$$
G(\cdot)=\nu_{1} w\left(\tau_{1}\right)+\nu_{2}\left(w\left(\tau_{2}\right)-\bar{w}\right)
$$

Because of the possibility of complete protection, now the government maximization problem is essentially different from that in Section II. The key point is that now the state variable $\dot{k}$ may be not continuously differentiable, therefore the appropriate way is to treat it as an optimal control problem with discontinuity. For this sort of problem, we need to consider the corner conditions additional to FOCs ${ }^{12}$ There maybe two corner points for this problem, $\tau_{1}$ and $\tau_{2}$. On the optimal path, for a corner point at time $\tau$, let $\tau^{-}$be the time just before $\tau$ and $\tau^{+}$the time just after $\tau$. The corner conditions at time $\tau$ include

$$
\begin{gathered}
\mu_{1}\left(\tau^{-}\right)=\mu_{1}\left(\tau^{+}\right)+G_{k(\tau)}, \mu_{2}\left(\tau^{-}\right)=\mu_{2}\left(\tau^{+}\right)+G_{w(\tau)} \\
H\left(\tau^{-}, \cdot\right)=H\left(\tau^{-}, \cdot\right)-G_{\tau},
\end{gathered}
$$

where the variables with subscripts denote corresponding derivatives. These conditions ensure that the transfer from one subarc to the other in the growth path is optimal. At the same time the continuity of the state variable is needed, i.e.

$$
k\left(\tau^{-}\right)=k\left(\tau^{+}\right)=k(\tau), w\left(\tau^{-}\right)=w\left(\tau^{+}\right)=w(\tau) .
$$

Then the characteristics of the equilibrium growth path is summarized in the following theorem.

THEOREM 5: there are three sequential stages in the dynamic equilibrium growth path.

1) In the first stage, Country A gives up investing in $S W S$, while the consumption growth rate, defense and predation behavior are just the same as those

${ }^{12}$ For the detail about control problem with discontinuity, see Hull (2003). 
under tolerant strategy, i.e.

$$
\begin{aligned}
F(t) & =\frac{\theta}{(1+\theta)^{2}} y(k(t)) \\
f(t) & =\frac{\theta}{(1+\theta)^{2}} y(k(t))-\frac{\bar{f}}{\theta} \\
p & =\frac{\theta}{1+\theta} \\
\gamma_{c} & =\frac{A \theta}{1+\theta}-\rho
\end{aligned}
$$

2) In the second stage, Country A keep investing in SWS, while the defense and predation behavior are still the same as those under tolerant strategy. The capital stock keep constant, denoted by $\bar{k}$, while consumption has a negative constant growth rate, $-\rho$.

3) In the third stage, after Country A setups SWS, his output is completely protected, while consumption and capital stock grow at constant rate just as those under friendly strategy, i.e.

$$
\begin{aligned}
F(t) & =0=f(t) \\
p & =1 \\
\gamma_{c} & =\gamma_{k}=A-\rho
\end{aligned}
$$

See the proof in the appendix.

There several important features for this growth path. First, country A will eventually protect his outcome completely, which implies that the complete protection will eventually dominant tolerant strategy. Since the growth path in theorem 5 is the solution of the central planner problem, it must be better for country A to completely protect itself at some level of the economy than just adopt tolerant strategy until infinite future as in theorem 4. Moreover, as the economy keep growing, complete protection will eventually occur regardless how high the SWS cost $\bar{w}$ is.

Secondly, there is an optimal time point for Country A to attain complete protection, which involves the balance between production and protection. At the first stage of development, Country A would not like to initiate SWS, because it's too expensive at that time and it's better to tolerant predation from other country. As the economy keep growing, the gains from a higher long term growth rate under complete protection dominate the temporary cost from enhancing defense capacity, then the transition to complete protection occurs.

Thirdly, the transitional dynamics from incomplete protection to complete protection exhibit some significant features. the consumption keeps the same constant growth rate in the first and second stages, which shows that country A 
tries to smooth consumption in different periods. But impressively, in the transitional process, consumption decreases at a constant rate, while the capital stock maintains staying at a constant level; at the turning point of $w=\bar{w}$, the consumption jumps up abruptly and is succeeded by the typical equilibrium growth path of neoclassical AK model where consumption and capital stock grow at the same constant rate. The underlying key point for the transitional dynamics is that Country A would like to compress period of investing in SWS as short as possible. That is, country A would like to postpone the initiation of SWS and so can input more resources in productive department and expand output. Once the SWS program begin, Country A invest no more in production such that the capital stock keep constant and the output is divided only into consumption and defense.

\section{Key Theoretical Implications}

This paper provides an analytical framework in which the international conflict and domestic growth are integrated in one model. It explains how to optimize the distribution of resources between the production and defense activities and the possible economic growth paths. This model has following theoretical implications at least.

\section{A. Determinants of Long Term Growth}

Nowadays, international circumstance is full of Hobbesian Rule and the conflicts have never disappeared. This model illustrates that the existence of external predator may make country A's growth in a very different way. Even if a country has good enough interior market environment and productive technology so that it can achieve stable economic growth without international conflicts, it will have a lower growth rate, and even could not achieve long term stable growth while there are external predators.

Therefore, in the environment of international conflicts, a country's long term growth is the result of the interaction between international factors and internal factors. Long term equilibrium growth path is determined by both the equilibrium of international conflicts and the balance between domestic consumption and investment. The country has to decide how to distribute its resource reasonably between the production and national defense. The external predation may reduce economic marginal output, so what growth phase does this country locate in is decided by this country's position in the international conflict equilibrium.

In the submissive equilibrium, this country does not pay the defense expenditure, or the defense expenditure is kept in a low level which can be ignored by the predator. (In reality, it can also be illustrated as that the limited military expenditure is only used to keep the internal social order.) In this situation, though

the country has a positive growth rate in the primary phase, as the increase of its output, its temptation to the external world becomes larger. Then there are 
more external predation and the level of economic security reduces. If it does not adjust security strategy, this country has to pay more and more "rent" to other country in exchange for the peace. Therefore, the proportion of being plundered increases, actual capital marginal return decreases and economic growth rate decreases gradually. If the government's national defense strategy refuses to adjust, the economy will reach a fixed stable state at last. In the tolerant equilibrium, the government has to balance carefully all along between the security policy and growth policy. On one hand, national defense expenditure and this country's gross output show relatively stable linear relation, i.e., the defense expenditure climbs with the increase of gross output. On the other hand, this country still tolerate that part of its property is being plundered by predator. Under the condition of high enough defense technology parameter and production technology parameter, the economy can realize long term stable growth. But the growth rate is lower than the growth rate in the neoclassical model without external predation. In the completely-protected equilibrium, the property of this country is totally safe. The economy can also attain a stable growth rate which is higher than the one in the tolerant equilibrium and is the same as the one under the environment without conflict. The direct cause leading these phases' transition in equilibrium is the capital stock's accumulation, which makes the defender has ability to realize a higher defense level. The mechanism is that higher defense technology parameter makes the realization of higher defense level become a better choice when the capital accumulation has reached a certain level.

\section{B. The Endogenous Adjustment of Defense Strategies}

The model captures that economic development causes one country's endogenous adjustment of defense strategies. Since different equilibria appear while the capital stock accumulates continuously, in different developing phases of a country, its government may face different options. When the capital stock is relatively low, according to theorem 4, having no other choice, the government has to choose the submissive strategy and give up the defense input. Because at that time, this country is so poor that the predators are not very interested in it. So the country's best choice is to rely only on the natural protection state. At that time, though the economy is unsafe, it can realize positive growth. When the gross capital stock increases to meet the requirement in Theorem 1, it is better for the government to choose to invest in national defense because if it adheres to the submissive strategy, economy will stop growing at last. If it switches to tolerant strategy, its safety will not become worse though it is still unsafe,, and it still has the possibility to realize continuous stable growth. As the country becomes wealthy enough, though tolerant equilibrium still exists theoretically, Theorem 5 illustrates that the whole society's welfare will be improved if it adopts completely-protected strategy. So this model predicts that the optimal growth path needs government to balance between security policy and development policy. A rational government should adopt different defense strategies in different development phases. 
When it is poor and less developed, it is more likely to choose the submissive strategy; after it has developed to a certain level, it is more likely to choose the tolerant strategy; and if it is strong enough, completely-protected strategy is a better choice.

The external environment also limits one country's policy choice. In this model, the quality of the external environment is mainly measured by $\bar{f}$. First of all, the higher $\bar{f}$ is, the less the defense expenditure, and the more the resource used in consumption and production, therefore, the social welfare will be improved. Secondly, according to Theorem 4, the more important meaning of $\bar{f}$ is that: it determines what kind of equilibrium growth path will arise as the amount of capital stock lies in some interval.

\section{Conclusion}

The paper tries to build a long term growth model in the environment with international conflicts. The analysis here shows that:

A country's long term growth is the result of the interactions of international factors and domestic factors. The long term equilibrium growth path is codetermined by the equilibrium of international conflicts and the balance between domestic consumption and investment.

According to the different characteristics of conflict equilibrium, equilibrium growth path may shows different phases, namely submissive equilibrium growth phase, tolerant equilibrium growth phase and fully-protected equilibrium growth phase. When the initial capital stock is relatively low, it is in submissive equilibrium growth phase in which there is always a part of wealth being plundered without defense investment, and the higher the output is, the lower the economic growth rate is. When the capital stock increase to a higher level, it enters tolerant equilibrium growth path, in which there is positive defense expenditure and a fixed proportion's output being plundered while the economy still has a positive growth rate. When the capital stock is high enough, the fully-protected equilibrium growth path may exist and the external predation is prevented completely, and the stable growth rate is higher than in the tolerant equilibrium. The government's different defense strategies lead to different growth scenarios. The equilibrium growth path needs the government to balance security policy and

growth policy. Continuous economic growth will cause endogenous adjustment of defense strategy, because a rational government will choose different strategies in different development phases. When the country is poor and backward, it chooses the submissive strategy. After it develops to a certain level, it switches to the tolerant strategy. When it is strong enough, the completely-protected strategy is a better choice.

\section{REFERENCES}

[Appelbaum, E. and Katz, E. (1987)] Appelbaum, E. and Katz, E. 1987. Seeking Rents by Setting Rents: The Political Economy of Rent Seeking. Economic 
Journal, 97, 685-99.

Baik, K. H. 1998. "Difference-Form Contest Success Functions and Effort Levels in Contests". European Journal of Political Economy, 14, 685-701.

Baik, K. H. and S. Lee. 2001. "Strategic Groups and Rent Dissipation". Economic Inquiry. 39, 672-84.

Barro, R. J. and X. Sala-i-Martin. 1999. Economic Growth. Cambridge, Massachusetts: the MIT Press.

Boulding, K.E. 1962. Conflict and defense: A General Theory, York: Harper and Row.

Dixit, A. 1987. "Strategic Behavior in Contests", American Economic Review. 77, 891-98.

[Friedman 1997] Friedman, D. 1997. "The Size and Shape of Nations". Journal of Political Economics, 85: 59-77.

Fudenberg, D. and J. Tirole. 1991. Game Theory. Cambridge: The MIT Press.

Garfinkel, M. R. 1990. "Arming as a Strategic Investment in a Cooperative Equilibrium". The American Economic Review. 80, 50-68.

Grossman, H. I. and M. Kim. 1995. "Swords or Plowshares? A Theory of the Security of Claims to Property". Journal of Political Economy. 103, 275-288.

Grossman, H. I. and M. Kim. 1996. "Predation and Accumulation". Journal of Economic Growth. 1, 333-351.

Grossman, H. I. and M. Kim. 1996. "Morality, Predation, and Welfare". Unpublished Workpaper.

Grossman, H. I. and M. Kim. 1996. "Predation and Production", in Michelle R.G. and S. Skaperdas eds. the Political Economy of Conflict and Appropriation. New York: Cambridge University Press.

Grossman, H. I. and M. Kim. 1989. "Conflict and Rent-Seeking Success Functions: Ratio vs. Difference Models of Relative Success". Public Choice. 63, 101112.

[15] Grossman, H. I. and M. Kim, "The Paradox of Power", Economics \& politics, 1991, 3, 177-200.

Grossman, H. I. and M. Kim. 1994. "The Dark Side of The Force", Economic Inquiry. 32, 1-10.

Grossman, H. I. and M. Kim. 2000. "The Macrotechnology of Conflict", The Journal of Conflict Resolution. 44, 773-791.

[Hull 2003] Hull, David G. 2003. The Optimal Control Theory for Applications. Spring-Verlag New York, Inc.

Loury, Glenn C. 1979. "Market Structure and Innovation", Quarterly Journal of Economics. 93, 395-410.

Macnail, E. S., J. C. Murdoch, C. R. Pi and T. Sandler. 1995. "Growth and Defense: Pooled Estimates for the NATO Alliance, 1951 88", Southern Economic 
Journal. $61,846^{\sim} 860$.

Mejia, D. and C. E. Posada. 2002. "Capital Destruction, Optimal Defense and Economic Growth", Workpaper.

Rosen, S. 1986. "Prizes and Incentives in Elimination Tournaments", American Economic Review, 76, 701-715.

Skaperdas, S. 1992. "Cooperation, Conflict and Power in the Absence of Property Rights". American Economic Review. 82, 720-739.

Skaperdas, S. 1996. "Contest Success Functions". Economic Theory. 7, 283-90.

Thompson, E. A. 1974. "Taxation and National Defense". Journal of Political Economy. 82, 755-782.

Skaperdas, S. 1980. "Efficient rent-seeking". In J. M. Buchanan, R.D. Tollison and G. Tullock eds. Toward a theory of the rent-seeking society. College Station, TX: Texas A\&M University Press. 97-112.

Sandler, Todd. \& Hartley, Keith. 2001. The Economics Of Defense. Beijing: Economic Science Press.

Angang Hu, \& Taoxiong Liu. 2003. the Comparison of Defense Capabilities of China, USA, Japan and India. Strategy and Management. 6, 40-45.

Nye. J. S. 2002. Understanding International Conflicts: An Introduction to Theory and History. Shanghai: Shanghai People Publishing House. 1-16.

\section{Mathematical Appendix}

\section{A1. Proof of Theorem 1, and 2}

Proof of Theorem 1

Substitute expression 9 into the family's problem, which leads to a standard $A k$ growth model. Find the first order conditions of Hamiltonian 8 ,

$$
\begin{gathered}
\frac{\partial \mathcal{H}}{\partial c}=0 \Rightarrow \frac{1}{c}-\mu=0 \\
\frac{\partial \mathcal{H}}{\partial k}=\rho \mu-\dot{\mu} \Rightarrow \mu\left(\frac{\theta}{1+\theta} A-\delta\right)=\rho \mu-\dot{\mu} .
\end{gathered}
$$

Then we can get 10 .

\section{Proof of Theorem 2}

Substitute 11 into the family's problem, which leads to a standard Solow model. From the first order conditions of Hamiltonian 12 (similarly as in the proof of Theorem 1), we have

$$
\frac{\dot{c}}{c}=\sqrt{\frac{A \bar{f}}{k}}-\rho-\delta,
$$


and from 2 .

$$
\dot{k}=\sqrt{\bar{f} A k}-c-\delta k
$$

The previous two differential equations are about $c$ and $k$. Solve them, together with the initial condition, to get a unique growth path and equations 12 .

\section{A2. Proof of Theorem 5}

1) First-order conditions

Get the FOCs from 17 ,

$$
\begin{gathered}
\frac{\partial \mathcal{H}}{\partial c}=0 \Rightarrow \frac{1}{c}-\left(\mu_{1}+\lambda_{4}\right)=0 \\
\frac{\partial \mathcal{H}}{\partial f}=0 \Rightarrow\left(\mu_{1}+\lambda_{4}\right)\left(p_{f} A k-1\right)+\lambda_{1}=0 \\
\frac{\partial \mathcal{H}}{\partial i_{w}}=0 \Rightarrow-\left(\mu_{1}+\lambda_{4}\right)+\mu_{2}+\lambda_{3}=0 \\
\frac{\partial \mathcal{H}}{\partial k}=\rho \mu_{1}-\dot{\mu}_{1} \Rightarrow\left(\mu_{1}+\lambda_{4}\right)(p A-\delta)=\rho \mu_{1}-\dot{\mu}_{1} \\
\frac{\partial \mathcal{H}}{\partial w}=\rho \mu_{2}-\dot{\mu}_{2} \Rightarrow \lambda_{2}=\rho \mu_{2}-\dot{\mu}_{2}
\end{gathered}
$$

(1) As the first case, we consider the economy before the country initiate the SWS. So $w=0, \lambda_{2}=0 ; i_{w}=0, \lambda_{3}>0 ; F=F^{\#}(k)$ or $F=F^{\&}(k)$.

We claim that $\lambda_{4}=0$ because inequality $(16)$ must be strict otherwise $k$ is constant. If $\lambda_{4}>0$ and $k$ is constant, $f$ should also be a constant from equation A2 either $\lambda_{1}$ be positive or 0 . Then from equation (15) $c$ must be constant. Then equation (A1) forces $\mu_{1}+\lambda_{4}$ to be constant, which is contradictory to equation (A4).

we also claim that $f>0 ; \lambda_{1}=0$. Since $* * * *$ shows that $p_{f}$ is decreasing in $f$ and $p_{f} y=1$ when $f=* * *$ as in $* * * *$, we know that $p_{f} y>1$ at $f=0$. So $f=0$ will lead to $\lambda_{1}<0$ from (A2), which is a contradiction.

Then for this case we have

$$
\left\{\begin{array}{l}
\frac{1}{c}-\mu_{1}=0 \\
p_{f} A k-1=0 \\
-\mu_{1}+\mu_{2}+\lambda_{3}=0 \\
\mu_{1}(p A-\delta)=\rho \mu_{1}-\dot{\mu}_{1} \\
0=\rho \mu_{2}-\dot{\mu}_{2}
\end{array}\right.
$$


Hence

$$
\begin{aligned}
f & =\frac{\theta}{(1+\theta)^{2}} A k \\
p & =\frac{\theta}{1+\theta}=\bar{p} \\
\frac{\dot{c}}{c} & =\frac{\theta A}{1+\theta}-\rho
\end{aligned}
$$

(2) The second case is after the country initiate the SWS but before finish it, i.e. $i_{w}>0, \lambda_{3}=0 ; w<\bar{w} ; \lambda_{2}=0$. We claim that $\lambda_{4}>0$ otherwise $\mu_{1}=\mu_{2}$ from A3, which is impossible for equation A4 and A5 to hold simultaneously. we also have $f>0 ; \lambda_{1}=0$, similarly as the previous case. So in this case

$$
\left\{\begin{array}{l}
\frac{1}{c}-\left(\mu_{1}+\lambda_{4}\right)=0 \\
p_{f} A k-1=0 \\
-\left(\mu_{1}+\lambda_{4}\right)+\mu_{2}=0 \\
\left(\mu_{1}+\lambda_{4}\right)(p A-\delta)=\rho \mu_{1}-\dot{\mu}_{1} \\
0=\rho \mu_{2}-\dot{\mu}_{2}
\end{array}\right.
$$

Hence, we have

$$
\begin{aligned}
f & =\frac{\theta}{(1+\theta)^{2}} A k \\
p & =\frac{\theta}{1+\theta} \\
\dot{c} & =\quad-\rho .
\end{aligned}
$$

(3) The third case is after the country finish the SWS, i.e. $w=\bar{w}, \lambda_{2}>0$. Then $F=0, F_{k}=0, p=1, p_{f}=0$, and $i_{w}=0, \lambda_{3}>0$. Equation (A2) implies $\lambda_{1}=\mu_{1}+\lambda_{4}>0$, since we know $\mu_{1} \neq 0$ from equation (A4). So $f=0$.

At the same time, $\lambda_{4}=0$ must hold because inequality 16 must be strict. If not, that means $k$ is constant and $c$ is also constant from equation 15 . Then equation A1 forces $\mu_{1}+\lambda_{4}$ to be constant, which is contradictory to equation A4. So

$$
\left\{\begin{array}{l}
\frac{1}{c}-\mu_{1}=0 \\
-\mu_{1}+\lambda_{1}=0 \\
-\mu_{1}+\mu_{2}+\lambda_{3}=0 \\
\mu_{1} A=\rho \mu_{1}-\dot{\mu}_{1} \\
\lambda_{2}=\rho \mu_{2}-\dot{\mu}_{2}
\end{array}\right.
$$


Hence,

$$
\begin{aligned}
& f=0 \\
& p=1 \\
& \frac{\dot{c}}{c}=A-\delta-p(f, F(k, w)) \rho .
\end{aligned}
$$

2) Corner Conditions

We have two corner points at time $\tau_{1}$ and $\tau_{2}$.

a) From case 1 to case 2 at $\tau_{1}$

Equations (21), (20), (A7), A9 and slackness conditions for both cases imply

$$
\mu_{1}\left(\tau_{1}^{-}\right)=\mu_{1}\left(\tau_{1}^{+}\right)
$$

$\operatorname{lnc}\left(\tau_{1}^{-}\right)+\mu_{1}\left(\tau_{1}^{-}\right)\left[p\left(\tau_{1}\right) y\left(\tau_{1}\right)-f\left(\tau_{1}\right)-c\left(\tau_{1}^{-}\right)\right]=\operatorname{lnc}\left(\tau_{1}^{+}\right)+\mu_{2}\left(t_{2}^{+}\right) i_{w}\left(\tau_{1}^{+}\right)$.

From equations (A6) and $\mathrm{A} 8$, we have $1 / c\left(\tau_{1}^{-}\right)=\mu_{1}\left(\tau_{1}^{-}\right), 1 / c\left(\tau_{1}^{+}\right)=$ $\mu_{2}\left(\tau_{1}^{+}\right), i_{w}\left(t_{1}^{+}\right)=p\left(\tau_{1}\right) y\left(\tau_{1}\right)-f\left(\tau_{1}\right)-c\left(\tau_{1}^{-}\right)$. Hence the previous corner condition can be written as

$$
\operatorname{lnc}\left(\tau_{1}^{-}\right)+\frac{1}{c\left(\tau_{1}^{-}\right)}\left[\bar{p} y\left(\tau_{1}\right)-f\left(\tau_{1}\right)\right]=\ln c\left(\tau_{1}^{+}\right)+\frac{1}{c\left(\tau_{1}^{+}\right)}\left[\bar{p} y\left(\tau_{1}\right)-f\left(\tau_{1}\right)\right],
$$

from which we can deduce that

$$
c\left(\tau_{1}^{-}\right)=c\left(\tau_{1}^{+}\right) \equiv c\left(\tau_{1}\right) .
$$

b) From case 2 to case $3 \tau_{2}$

Similarly as previous, we have

$$
\mu_{1}\left(\tau_{2}^{-}\right)=\mu_{1}\left(\tau_{2}^{+}\right)
$$

$\operatorname{lnc}\left(\tau_{2}^{-}\right)+\mu\left(\tau_{2}^{-}\right) i_{w}\left(\tau_{2}^{-}\right)=\operatorname{lnc}\left(\tau_{2}^{+}\right)+\mu\left(\tau_{2}^{+}\right)\left[p\left(\tau_{2}\right) y\left(\tau_{2}\right)-f\left(\tau_{2}\right)-c\left(\tau_{2}^{+}\right)\right]$,

The second equation can be written as

$$
\ln c\left(\tau_{2}^{-}\right)+\frac{\bar{p} y\left(\tau_{2}\right)-f\left(\tau_{2}\right)}{c\left(\tau_{2}^{-}\right)}=\ln c\left(\tau_{2}^{+}\right)+\frac{y\left(\tau_{2}\right)}{c\left(\tau_{2}^{+}\right)} .
$$


where from equations in A9

$$
c\left(\tau_{2}^{-}\right)=c(0) e^{\gamma_{c} \tau_{1}-\rho\left(\tau_{2}-\tau_{1}\right)}
$$

3) Determining the growth path

Equations A6, A8, A10mplies

$$
\begin{aligned}
0 \leq t_{\mathrm{i}} \tau_{1}: & \mu_{1}(t)=1 / c(t) \\
\tau_{1} \leq t<\tau_{2}: & \mu_{2}(t)=1 / c(t) \\
\tau_{2} \leq t: & \mu_{1}(t)=1 / c(t)
\end{aligned}
$$

Since $c\left(\tau_{1}^{-}\right)=c\left(\tau_{1}^{+}\right)$,

$$
\mu_{1}\left(\tau_{1}^{-}\right)=\mu_{1}\left(\tau_{1}^{+}\right)+\lambda_{4}=\mu_{2}\left(\tau_{1}^{+}\right)
$$

From the third and forth lines in A8, between time $\tau_{1}$ and $\tau_{2}$

$$
\mu_{2}(t) p A=\rho \mu_{1}-\dot{\mu}_{1}
$$

Solve this differential equation for $\mu_{1}$ to get

$$
\mu_{1}\left(\tau_{2}^{-}\right)=\mu_{1}\left(\tau_{1}^{+}\right) e^{\rho \tau_{2}}+e^{\rho t} \int_{\tau_{1}}^{\tau_{2}} \mu_{2}(t) p A e^{-\rho t} d t
$$

From equations above, A16, A12 and A13.

$$
\begin{aligned}
\frac{1}{c\left(\tau_{2}^{+}\right)} & =\mu_{1}\left(\tau_{2}^{+}\right)=\mu_{1}\left(\tau_{2}^{-}\right) \\
& =\mu_{1}\left(\tau_{1}^{+}\right) e^{\rho\left(\tau_{2}-\tau_{1}\right)}+e^{\rho\left(\tau_{2}-\tau_{1}\right)} \int_{\tau_{1}}^{\tau_{2}} \mu_{2}(t) p A e^{-\rho t} d t \\
& =\frac{1}{c\left(\tau_{1}^{-}\right)} e^{\rho\left(\tau_{2}-\tau_{1}\right)}+e^{\rho\left(\tau_{2}-\tau_{1}\right)} \int_{\tau_{1}}^{\tau_{2}} \frac{1}{c(t)} p A e^{-\rho t} d t
\end{aligned}
$$

Hence

$$
\frac{1}{c\left(\tau_{2}^{+}\right)}=\frac{1}{c\left(\tau_{1}^{-}\right)} e_{23}^{\rho\left(\tau_{2}-\tau_{1}\right)}+e^{\rho\left(\tau_{2}-\tau_{1}\right)} \int_{\tau_{1}}^{\tau_{2}} \frac{1}{c\left(\tau_{1}^{-}\right) e^{-\rho t}} p A e^{-\rho t} d t
$$




$$
\begin{aligned}
& 0 \leq t_{\mathrm{i}} \tau_{1}: \quad \quad \dot{k}=\frac{\theta}{1+\theta} A k-c(t) \\
& \frac{\dot{c}}{c}=\frac{\theta A}{1+\theta}-\rho \\
& \tau_{1} \leq t<\tau_{2}: \quad \quad \dot{k}=\frac{\theta}{1+\theta} A k-c(t)-i_{w} \\
& \frac{\dot{c}}{c}=-\rho \\
& \dot{w}=i_{w} \\
& \tau_{2} \leq t: \quad \dot{k}=A k-c(t) \\
& \frac{\dot{c}}{c}=A-\rho
\end{aligned}
$$

Boundary conditions

$(\mathrm{A} 19) \quad k(0)=k_{0}$

$$
w\left(\tau_{1}\right)=0 ; w\left(\tau_{2}\right)=\bar{w} \quad \lim _{T \rightarrow \infty} \mu_{1}(T) k(T)=0
$$

Equation A17, differential equations in A18 and boundary conditions in A19 determine the unique growth path of the economy. 